\title{
Confiabilidade de medidas faciais indiretas obtidas por uma única estereofotografia digital tridimensional em relação a medidas faciais diretas padrão, em crianças
}

\author{
Reliability of indirect facial measurements \\ obtained by a single three-dimensional digital \\ stereophotograph in relation to standard \\ direct facial measures in children
}

\section{Confiabilidad de mediciones faciales indirectas obtenidas por una única estereofotografía digital tridimensional en relación a medidas faciales directas estándar en niños}

\author{
Carolina Tavares Costa* \\ Hilton Justino da Silva* \\ Adriana Camargo Gomes*
}

Jodeh DS, Rottgers SA. High-Fidelity Anthropometric Facial Measurements Can Be Obtained From a Single Stereophotograph From the Vectra H1 3-Dimensional Camera. Cleft Palate Craniofac J. 2019;1:1-7.

A antropometria facial refere-se ao estudo de medidas e proporções da face, o que é útil em várias áreas da saúde, como Odontologia, Medicina, Fonoaudiologia, entre outras, para avaliação de anomalias congênitas, deformidades faciais adquiridas, diagnóstico, plano de tratamento e comparações pré e pós tratamento, ou estágios de crescimento craniofacial. ${ }^{1-5}$

* Universidade Federal do Pernambuco, Recife, PE, Brasil.

E-mail para correspondência: Carolina Tavares Costa - carollcosta@hotmail.com Recebido: 10/10/2019

Aprovado: 21/01/2019 
A despeito de serem confiáveis, de baixo custo e com extenso banco de dados normativos, as medições faciais diretas, por meio de instrumentos tradicionais (por exemplo, fitas métricas e paquímetros) cuja utilização, até recentemente, era a opção para esse exame, ${ }^{1,5-7}$ são apontadas como um método desvantajoso, no artigo resenhado, por ser demorado, incompatível ao fluxo da prática clínica e pela necessidade de aceitação do paciente infantil ao exame.

Em contrapartida, os autores, médicos da Divisão de Cirurgia Plástica e Reconstrutiva, do Hospital Johns Hopkins All Children, St. Petersburg, FL, USA, apresentam a fotogrametria digital 3D como uma técnica mais vantajosa em relação aos métodos diretos convencionais para o estudo e documentação de distúrbios craniofaciais, devido à rápida velocidade de aquisição de imagem, reduzindo os movimentos, além de eliminar a necessidade de contato direto com o sujeito, evitando deformação dos tecidos moles.

Fotogrametrias 3D permitem a colocação de pontos em imagens de superfície digital, os quais podem ser ampliados e girados, usando-se o software 3dMD, facilitando a visualização e identificação de pontos de referência, o que não é possível na antropometria direta. Esses marcos podem ser arquivados como coordenadas para análises subsequentes e as medições digitais podem ser repetidas sem incomodar o paciente. Além disso, a qualidade da imagem pode ser visualizada imediatamente após sua aquisição, para determinar se houve distorção, e isso possibilita nova tomada fotográfica, em seguida, reduzindo o tempo do exame e com melhor aproveitamento do resultado. ${ }^{1,7-9}$

Por outro lado, as desvantagens apontadas no artigo para esse método, são: seu alto custo; possibilidade de incompatibilidade na definição dos pontos anatômicos por virem padronizados de fábrica; e dificuldade em gerar imagens de superfícies transparentes, brilhantes e sombreadas.

Os autores também afirmam que a despeito do crescente interesse pela imagem 3D de superfície no campo da cirurgia reconstrutiva, há apenas um número limitado de estudos que avaliam sua reprodutibilidade, em comparação com outros métodos, e sua confiabilidade inter avaliadores. As medidas de confiabilidade das fotos devem ser iguais ou diferentes, no máximo em $1 \mathrm{~mm}$, das medidas diretas, e menor que $2^{0}$ para medidas angulares. $\mathrm{O}$ coeficiente de correlação entre avaliadores deve ser de $\pm 0,91.7,8$

De acordo com o artigo analisado, os objetivos foram divididos em três momentos: (1) Aferição das medidas antropométricas faciais diretas, por meio de paquímetro Castroviejo e régua; (2) Aferição das medidas das imagens 3D obtidas a partir da câmera Vectra H1, em uma única tomada frontal e outra submentual (as quais geram duas imagens cada uma). Ambas aferições realizadas pelo mesmo pesquisador, autor sênior e cirurgião plástico craniofacial pediátrico, o qual se baseou em quatorze distâncias lineares (dez medianas e quatro bilaterais) baseadas nos marcos antropométricos padrão, definidos por Farkas (1994) e Mulliken et al. (2001); (3) Comparação entre as medidas, por análise estatística de Correlação Intraclasse. A avaliação do Coeficiente de correlação intraclasse (CCI) foi utilizada para determinar a confiabilidade intra examinador das imagens 3D duplicadas a partir de vistas frontais e submentuais. O teste de Shapiro-Wilk foi utilizado para avaliar a normalidade da distribuição dos dados. Foi usado o SAS versão 9.4 (SAS Institute Inc, 2018) para a análise estatística, com nível de significância de 5\%. ${ }^{1-9}$

No entanto, os avaliadores não levaram em consideração a intubação por via oral, a qual pode modificar as medidas faciais medianas, de lábios, principalmente, já que os mesmos devem permanecer levemente selados para obtenção correta das medidas. Um procedimento craniofacial representa alto grau de precisão para planejamento operacional e resultados. Na cirurgia de fissurados, acredita-se que $1 \mathrm{~mm}$ de assimetria do arco de Cupido é observável na distância de conversação. ${ }^{1-9}$

Ainda, de acordo com os autores do artigo resenhado, o Vectra $\mathrm{H} 1$ poderia ser usado para obter medições precisas de estruturas faciais centrais com a facilidade de uma única estereofotografia. $\mathrm{O}$ dispositivo não precisaria estar conectado a um laptop no momento de captura da imagem e poderia ser posteriormente conectado ao laptop para transferência de imagens e reconstrução de modelos 3D. Poderia ser facilmente transportado entre as salas da clínica e a sala de cirurgia, e imagens poderiam ser obtidas sem a preocupação com o reposicionamento da criança. Isso maximizaria a aplicabilidade da estereofotogrametria e análise antropométrica de crianças e lactentes. Todos esses fatores são relevantes e justificam o estudo realizado. 
Após aprovação do Comitê de Ética e obtenção do Termo de Consentimento Livre e Esclarecido assinado pelos cuidadores dos pacientes, os pesquisadores do artigo recrutaram vinte crianças (treze meninas e sete meninos) entre zero e dez anos de idade, do Hospital Johns Hopkins All Children, Estados Unidos. Todas apresentando morfologia nasolabial normal, submetidas a cirurgias eletivas, que incluíam excisão de nevus congênito, excisão de cisto dermóide, e excisão de corpo estranho. Os pacientes excluídos foram os que possuíam fissuras de lábio e ou palato, com más-formações craniofaciais e com síndromes identificadas. Esse estudo antropométrico prospectivo foi realizado de agosto de 2017 a agosto de 2018. O artigo não informa o número do registro no Comitê de Ética, não demonstra se a amostra foi por conveniência ou se houve cálculo amostral, e nem se o estudo foi aleatório ou randomizado.

Sob anestesia geral para os procedimentos eletivos, os pacientes foram fotografados com a câmera Vectra H1 3D (Canfield Imaging) e quatro fotografias 3D (duas na visão submentual e duas na visão frontal) foram realizadas. Cada tomada produz duas imagens da mesma área, para gerar uma superfície facial 3D separada, o que é diferente do que o fabricante recomenda, que seriam três estereofotografias (seis imagens) de diferentes perspectivas para gerar uma única superfície em 3D. As imagens foram capturadas sem a câmera estar conectada ao laptop, a qual seria conectada a posteriori para a transferência das imagens e a construção das superfícies 3D usando o Software de imagem Vectra. Isso demonstra o pioneirismo da pesquisa em questão.

Os resultados do estudo, segundo os avaliadores, apontaram que duas imagens (uma frontal e uma submentual) foram excluídas por apresentarem distorção. Mas confirmam que medidas faciais lineares podem ser obtidas a partir de uma única estereofotografia tirada usando a câmera portátil Vectra H1 3D. Medidas tomadas de imagens 3D reconstruídas foram precisas quando comparadas a medidas lineares tomadas com antropometria direta. Isso indica, de acordo com o artigo, que as imagens 3D tiradas usando uma captura única é uma técnica confiável e promete melhorar a integração da estereofotogrametria em uma clínica de alto fluxo de trabalho e a capacidade de aplicar essa técnica à avaliação de neonatos e crianças pequenas.
Todavia, o estudo não abordou questões bastante significativas como, setorizar as medidas de acordo com sexo e idade, o que pode implicar em vieses e conclusões equivocadas. Na literatura, estes fatores influenciam diretamente na antropometria facial. Crianças do sexo feminino geralmente apresentam a maioria das medidas faciais inferiores às do sexo oposto. A idade também é um fator determinante para o crescimento craniofacial. Uma arcada edêntula de um bebê, gera medidas faciais bem menores que uma arcada de uma criança com dentição mista, o que é o caso das crianças de cinco a dez anos, incluídas nesse estudo. ${ }^{3-5,10}$ Uma sugestão seria separar as tabelas por grupos de idades, ou ainda, em fases de dentição, por exemplo: arcada edêntula; dentição decídua; dentição mista (com erupção completa dos primeiros molares permanentes). A cada nascimento dentário, aumenta-se a dimensão vertical da criança, aumentando-se assim, suas alturas faciais e consequentemente, suas medidas. E muitos estudos ainda apontam que as médias das medidas antropométricas orofaciais aumentam de acordo com a idade. ${ }^{3-5,10}$

Outro viés foi encontrado nos fatores de exclusão. De acordo com vários estudos, seria interessante excluir também sujeitos com mordida aberta anterior, sobremordida e/ou mordida cruzada, que modificam as alturas orofaciais; bem como sujeitos em tratamento ortodôntico (pois modifica a configuração facial durante o tratamento); com histórico de trauma facial; pacientes em tratamento fonoaudiológico (pode modificar a altura labial, já que há terapias com massagens para alongamento de lábios superior e inferior, no intuito de auxiliar no selamento labial de respiradores orais, por exemplo); Respiradores orais (apresentam desequilíbrio muscular que podem modificar ossos nasais, falta de selamento labial, podem apresentar excessiva altura inferior da face e a altura do lábio superior pode se encontrar retraída ou encurtada, alterando assim, suas medidas). Já nos fatores de inclusão, poderiam ter adicionado também sujeitos sem más-oclusões dentárias, para minimizar o risco de erros. ${ }^{3-5}$

O fato do título não obter a faixa etária que seria estudada no artigo, generaliza bastante o tipo de população, tornando-se menos atrativo para quem necessita de pesquisa com determinado público específico. Sua introdução possui um referencial teórico rico, definindo os pontos a serem analisados, tais como os tipos de aferições das medidas 
antropométricas faciais, trazendo as vantagens e desvantagens de cada método utilizado.

No entanto, o estudo é relevante na ampliação de subsídios que visam facilitar o fluxo do trabalho clínico, principalmente por sua acurácia, precisão, reprodutibilidade, portabilidade e aplicabilidade em pacientes pediátricos. Ademais, os autores apresentam as limitações da pesquisa, recomendando, para futuros estudos, a tomada de várias imagens, nas perspectivas frontal e submentual, ao invés de apenas uma tomada estereofotográfica para cada região, para diminuir o risco distorções das imagens e de perda de dados, além de permitir a outros pesquisadores a escolha da melhor estereografia.

Porém, observaram-se algumas falhas metodológicas que necessitam ser controladas futuramente, principalmente quando se trata de planejamentos cirúrgicos. Os principais pontos críticos referem-se aos vieses discorridos anteriormente, além do que a utilização de apenas uma tomada estereofotográfica para cada região a ser estudada ainda é controversa por existirem riscos de distorções e, com isso, perda de dados relevantes ao estudo. ${ }^{7,8}$

A despeito das ressalvas metodológicas aqui apontadas, o artigo propõe uma abordagem bastante relevante para os profissionais de Saúde, que trabalham com medidas faciais.

\section{Referências}

1 Villanueva-Bonilla S, Saavedra-Layera L, Vergara-Núñez C. Comparación de mediciones antropométricas directa y con sistema de imagen 3D, en adultos jóvenes. Rev. P.I.R.O. 2018; 11 (1): 16-19.

2 Ramires RR et al. Proposta para determinação do tipo facial a partir da antropometria. J Soc Bras Fonoaudiol. 2011; 23 (3): $1-6$

3 Brons S et al. Methods to Quantify Soft-Tissue Based Facial Growth and Treatment Outcomes in Children: A Systematic Review. PLoS ONE. 2014; 27; 9 (2): e89602.

4 Bossle $\mathrm{R}$ et al. Medidas antropométricas orofaciais em crianças de três a cinco anos de idade. Rev. CEFAC. 2015; 17(3): 899-906.

5 Cattoni DM. Exame Fonoaudiológico: medidas faciais em crianças leucodermas sem queixas fonoaudiológicas [dissertação de Mestrado]. São Paulo: Universidade de São Paulo, Faculdade de Medicina; 2003.

6 Weinberg S M. 3D stereophotogrammetry versus traditional craniofacial anthropometry: Comparing measurements from the 3D facial norms database to Farkas's North American norms. Am J Orthod Dentofacial Orthop. 2019; 155(5): 693-701.

7 Wong JY et al. Validity and Reliability of Craniofacial Anthropometric Measurement of 3D Digital Photogrammetric Images. Cleft Palate Craniofac J. 2008; 45(3): 232-9.

8 Düppe K, Becker M, Schönmeyr B. Evaluation of Facial Anthropometry Using Three-Dimensional Photogrammetry and Direct Measuring Techniques. J Craniofac Surg. 2018; 29(5): 1245-1251.

9 Dindaroğlu, F et al. Accuracy and reliability of 3D stereophotogrammetry: A comparison to direct anthropometry and 2D photogrammetry. Angle Orthod. 2016; 86(3): 487-494.

10 Tavano PT. Anatomia do recém nascido e da criança: características gerais. Ensaios e Ciência: C. Biológicas, Agrárias e da Saúde. 2008; 12 (1): 63-74. 